\title{
REFLEXÕES SOBRE A NOÇÃO BERMANIANA DE RELAÇÃO À LUZ DO CONCEITO DERRIDIANO DE HOSPITALIDADE
}

\author{
Simone Christina Petry
}

\section{Estudos da tradução, Antoine Berman e a questão da relação \\ Inicialmente inseridas em discursos ditos logocêntricos, quando o fazer} tradutório era apenas mais um objeto de pesquisa pertencente quase que exclusivamente aos estudos linguísticos, as teorias voltadas para a reflexão sobre a tradução, grosso modo, tratavam da atividade como uma simples transferência de signos e significados e, nesse processo, o tradutor tinha um papel, quase mecânico, de mediador: bastava que possuísse um conhecimento gramatical adequado de dois, ou mais, idiomas e um bom dicionário para realizar a sua tarefa. A busca por uma fidelidade ao texto original dava a este uma conotação sagrada e a tradução era (em muitos casos, ainda é), numa condição hierárquica, considerada inferior; considerada até mesmo impossível perante os obstáculos linguísticos, inevitáveis; porém sabia-se (sabe-se) necessária.

Com a problematização da postura logocêntrica advinda de outros discursos, em especial aqueles de viés desconstrucionista, o papel do tradutor passou a ser tema de destaque nas pesquisas sobre o fazer tradutório. E a tradução, que até então era tida como uma atividade que não necessitava de grandes reflexões, pois bastava que fosse praticada, passa a ser percebida como um espaço no e do qual discussões com relevância científica poderiam brotar. Para além disso, já se fazia notável para alguns teóricos a necessidade de uma área, de uma disciplina, que abordasse o assunto de forma a possibilitar um espaço para uma teoria que se ocupasse apenas de questões referentes à tradução, objetivando reflexões que alimentassem a prática e que enriquecessem a discussão teórica, promovendo assim algo que se aproximasse de uma ciência do traduzir.

Por conta disso, em meados do século XX, mais precisamente entre as décadas de setenta e oitenta, teve início um processo de institucionalização de uma área voltada especificamente para os estudos da tradução. Nesse cenário o tradutor francês Antoine Berman ganha destaque como um dos mais influentes pensadores da tradução da contemporaneidade. Para ele, a despeito de o pensamento moderno estar intrinsecamente ligado aos problemas de tradução e ao que ele chamaria de espaço da 
tradução, a prática tradutória ainda era interrogada, na maioria das vezes, a partir de outras áreas e não a partir do seu próprio fazer.

Berman, então, escreve em 1981 um ensaio intitulado "A tradução em manifesto". Sua proposta, nesse ensaio, é a de refletir sobre o fazer tradutório a partir de uma visão moderna, mas que dialogue com o passado tendo em vista uma compreensão do si-mesmo (Berman, 2002 [1984]: 12) — diálogo desenvolvido com a tradição do pensamento romântico alemão sobre tradução (séculos XVIII e XIX), em especial com as reflexões do filósofo Friedrich Schleiermacher. Essa reflexão tem em vista encaminhar a discussão sobre o fazer tradutório para além da elaboração de uma teoria sistemática, prescritiva, com o intuito de auxiliar a prática tradutória.

Vale lembrar que o contexto alemão que Berman toma como base para sua reflexão se fundamenta no conceito da Bildung, formação cultural, que, conforme resume o teórico:

[... é] ao mesmo tempo um processo e seu resultado. Pela Bildung, um indivíduo, um povo, uma nação, mas também uma língua, uma literatura, uma obra de arte em geral se formam e adquirem assim uma forma, uma Bild. A Bildung é sempre um movimento em direção a uma forma que é uma forma própria. (p. 80, grifos do autor)

E, nesse âmbito, Schleiermacher, quando defende o seu modelo estrangeirizante de tradução, opõe-se ao modelo francês das belles infidèles, modelo dominante da época; e é esse mesmo modelo que vigora na França do século XX, onde Berman elabora seu discurso e sua crítica sobre tradução.

A partir disso, o teórico encaminha sua discussão no sentido de refletir sobre e de experienciar o fazer tradutório e, desse modo, abrir possibilidades para que a tradução tenha "acesso a seu próprio ser" (p. 17). Ou seja, tornando possível que a tradução encontre seu espaço e sua essência: “[...] a essência da tradução é ser abertura, diálogo, mestiçagem, descentralização. Ela é relação, ou não é nada" (p. 17, grifo do autor).

Com isso, o teórico institui uma discussão que se projeta a partir de uma visada da tradução como relação ${ }^{1}$. Berman institui essa condição para a tradução não no sentido de ser o primeiro a defender essa possibilidade — pois ao analisarmos a história

\footnotetext{
${ }^{1}$ Ao longo da tese intitulada Solidão e Encontro: prática e espaço da crítica da tradução literária (2004), Mauricio Mendonça Cardozo já aponta para a importância dessa perspectiva relacional de leitura da reflexão bermaniana.
} 
da tradução, principalmente a da Alemanha romântica, é notável o quanto o tema aparece, mesmo que de forma implícita, no discurso de muitos dos pensadores da época —, mas no sentido de ser um dos maiores responsáveis por uma explicitação dessa perspectiva no contexto do pensamento contemporâneo sobe tradução.

Para considerar a tradução a partir de uma noção de relação, conforme apresentado na máxima bermaniana, precisamos, primeiramente, entender mais atentamente quais as implicações que o termo relação traz para o fazer tradutório. E também, num segundo momento, entender o que significa o nada nesse espaço, visto que, em consequência dessa máxima, caso a tradução não seja relação ela será nada. Assim, não será tradução? Não será relação?

Para se compreender a noção de relação proposta por Berman, no ensaio "A tradução em manifesto" (Berman, 2002 [1984]: 11-25), dois conceitos elaborados pelo autor são indispensáveis: o da tradução etnocêntrica e o da visada ética da tradução.

Nesse ensaio, o autor defende para a tradução uma ética positiva, que é alcançada pelo tradutor se este se guiar pelo que ele chama de visada ética da tradução, o que resultaria, segundo ele, numa "boa tradução". A visada ética é elaborada a partir da seguinte reflexão: uma ética da tradução, para Berman, consistiria "em resgatar, afirmar e defender a pura visada da tradução como tal” (p. 17, grifo meu). A visada da tradução, ainda segundo o teórico, significa "abrir no nível da escrita uma certa relação com o Outro, fecundar o próprio pela mediação do Estrangeiro [...]" (p. 17, grifo do autor). No desenvolvimento da sua reflexão, o teórico explicita o conceito de visada ética da tradução, que seria, na leitura aqui proposta, uma defesa da tradução como abertura ao Outro, enquanto relação com o Outro. É em defesa da visada ética que ele vai criticar e analisar as teorias da tradução e as traduções, que ele chama de tradicionais, ou etnocêntricas, para através disso estabelecer um espaço verdadeiro da tradução, ou até mesmo uma especificidade da tradução.

Nesse sentido, uma ética negativa seria aquela para a qual se direciona uma opção equivocada do tradutor ao se apropriar do outro, o que resultaria numa "má tradução", ou, fazendo uso da terminologia do autor, resultaria numa tradução etnocêntrica.

Grosso modo, podemos compreender os pressupostos de Berman da seguinte maneira: uma tradução etnocêntrica é aquela que não promove abertura ao outro, portanto, apropria-se do outro de tal modo a apagar todo traço que o caracterize como estrangeiro. Esse apagamento resulta numa "má tradução", ou, nos termos de Berman, 
num nada; já uma visada ética da tradução, ao promover uma abertura ao outro sem dele se apropriar - a apropriação na reflexão bermaniana seria um traço especificamente etnocêntrico —, manteria visíveis os traços estrangeiros do outro, resultando, assim, numa "boa tradução", numa tradução elaborada a partir de um movimento de relação.

Porém, em meio à defesa de uma essência relacional da tradução, Berman problematiza a possibilidade de se atingir o intento dessa visada ética quando diz:

Está na hora de meditar sobre este estatuto reprimido da tradução e sobre o conjunto de 'resistências' que ele testemunha. $\mathrm{O}$ que poderia ser formulado assim: toda cultura resiste à tradução mesmo que necessite essencialmente dela. A própria visada da tradução - abrir no nível da escrita uma certa relação com o Outro, fecundar o Próprio pela mediação do Estrangeiro - choca-se de frente com a estrutura etnocêntrica de qualquer cultura, ou essa espécie de narcisismo que faz com que toda sociedade deseje ser um Todo puro e não misturado. Na tradução, há alguma coisa da violência da mestiçagem. (Berman, 2002 [1984]: 16, grifo do autor)

Berman se opõe a uma atitude dominantemente etnocêntrica, mas não pressupõe a possibilidade de uma tradução que também não seja, em alguma medida, etnocêntrica. Porque não é possível se desvincular totalmente de pressupostos ideológicos — constitutivos de uma opção etnocêntrica —, já que eles estão enraizados nas inúmeras culturas, e o tradutor, que está intimamente conectado a sua própria cultura, não escapa a essa condição.

Flagram-se, então, dois movimentos característicos no discurso bermaniano: um de dimensão política, que é justamente onde se encaixa a problematização que o autor faz da sua visada ética da tradução, ao abordar questões ideológicas e culturais; e um de dimensão filosófica, que comporta o conceito de tradução como relação.

Para retomar a atenção àquilo que estamos chamando de dimensão filosófica do discurso bermaniano, como já destacamos anteriormente, há uma questão a ser problematizada: a noção de relação. De acordo com a nossa percepção, essa questão se desdobra em outras duas que vêm compor a visada ética da tradução:

(i) a questão da condicionalidade da tradução como relação: o autor supõe que a relação só se dá na condição de não acontecer uma apropriação do outro pelo próprio. Ao mesmo tempo, para o teórico, a tradução deve ser incondicionalmente uma relação, do contrário não é nada. Com isso, nos perguntamos: essa relação que Berman propõe seria uma relação incondicional? Seria possível impor uma condição para se determinar uma tradução como relação?; 
(ii) a questão do alcance do outro: ao afirmar a necessidade de uma tradução como relação não conter, em qualquer grau, uma apropriação do outro pelo próprio, Berman, de certo modo, pressupõe a possibilidade de um alcance desse outro na sua totalidade, sem que nada do próprio seja projetado no outro durante o desenrolar dessa relação. Perguntamo-nos: até que ponto isso é possível? Ou ainda, se pensarmos que Berman ao problematizar a possibilidade de uma visada ética admite certo etnocentrismo na tradução, desde que com grau minimizado, a pergunta é: seria possível o próprio ter total controle do quanto irá se apropriar, ou não, do outro? E ainda: numa relação é possível mensurar o quanto do próprio e o quanto do outro se sobressai? Para tentar uma resposta a essas questões nos parece que outras duas clamam por uma maior reflexão: o que constitui o próprio? O que constitui o outro?

\section{Um ato de relação e um ato de hospitalidade}

Com vistas a estender nossa reflexão sobre a noção de relação é possível conjecturar que o ato de receber o outro é uma forma, também, de dar abertura ao outro, ou ainda, de dar entrada ao outro. Dar entrada ao outro, por sua vez, pode ser entendido como um ato de hospitalidade para com ele, no sentido de acolhê-lo em um determinado espaço. A hospitalidade pressupõe, seguindo por um sentido comum do termo, que esse outro precisa ser recepcionado com gentileza na casa daquele que o hospeda, e por aquele que o hospeda, a ponto de sentir-se no espaço que não é o seu como se estivesse na sua própria casa, como se fizesse parte da família que o está recebendo. Do mesmo modo, a relação com o outro que se estabelece durante a reflexão bermaniana implica num movimento de abertura que tem, entre outros fins, o objetivo de receber $\mathrm{o}$ estrangeiro a partir de uma atitude de respeito para com ele. Nas palavras de Berman: “[...] A eticidade reside no respeito, ou melhor, num certo respeito pelo original" (2007 (1985): 7). Assim, a tradução como relação, tomando como base a discussão elaborada até aqui, pode ser considerada também como um ato de hospitalidade.

Derrida, no texto Anne Dufourmantelle convida Jacques Derrida a falar Da Hospitalidade (2003), elabora uma reflexão sobre a questão do estrangeiro e a questão da hospitalidade incondicional. Primeiramente ele nos apresenta a questão do estrangeiro:

A questão do estrangeiro não seria uma questão de estrangeiro? Vinda do estrangeiro?

[...] antes de ser uma questão a ser tratada, antes de designar um conceito, um tema, a 
questão do estrangeiro é uma questão de estrangeiro, uma questão vinda do estrangeiro, e uma questão ao estrangeiro, dirigida ao estrangeiro. Como se o estrangeiro fosse, primeiramente, aquele que coloca a questão ou aquele a quem se endereça a primeira questão. [...] Mas também aquele que, ao colocar a primeira questão, me questiona. (Derrida, 2003: 5, grifos do autor)

Assim, ao refletir sobre a questão do estrangeiro, Derrida também coloca em causa a questão da alteridade, a condição do outro como estrangeiro. Porém, para fins deste artigo, cabe sublinhar o que entendemos como a noção de relação derridiana (Derrida, 2003): uma relação que inevitavelmente acontece durante um ato de hospitalidade, ato que, segundo o autor, só pode ser poético, i.e, é um trabalho a se realizar, um ato que está sempre em construção, um ato que está sempre no por vir.

Para esse filósofo, uma relação entre o próprio e o outro, ou melhor, entre o hóspede e o hospedeiro, só se dá se ambos se dispuserem ao enfrentamento de que toda relação carece. Enfrentamento porque, segundo Derrida, ao darmos passagem ao outro estaremos sempre a mercê de "um perigo e uma chance" (Perrone Moisés, 2007: 45) e, nesse caso, não temos como prever como se dará a relação que irá se instaurar a partir da abertura, $d a$ passagem e na passagem. Com isso, concluímos que $a$ ou $a s$ condições $d a$ relação e de relação só brotarão durante o processo de construção da relação, portanto, uma relação só se dá se aceitarmos enfrentar a sua condição principal que é a imprecisão, o imprevisto. E assim, podemos concluir que: se o próprio ou o outro não se expuserem ao imprevisto a relação não acontece. Poderíamos supor, então, que a noção de relação derridiana se encontra no local do nada bermaniano, no espaço onde tudo está por se construir. É lá, e somente lá que ela poderá acontecer. E deve acontecer, porque é na relação com o outro que o próprio se constitui e, por isso, para Derrida, a hospitalidade deve ser incondicional, apesar de todas as condições, como bem resume Perrone-Moisés:

A hospitalidade, isto é, a aceitação do outro em nossa casa, em nosso país, representa um perigo: o hóspede pode ser um ladrão ou um terrorista. Por outro lado, a hospitalidade é um imperativo ético e a chance de uma relação pacífica entre os homens. Mais que isso: a acolhida do outro é a condição da ipseidade, já que não há sujeito sem o reconhecimento do outro. A hospitalidade deve ser incondicional. (2007: p. 44-5)

Voltando à questão do estrangeiro, quando Derrida diz ser o estrangeiro aquele que questiona e também aquele que é questionado, ele está justamente falando da questão do enfrentamento. Pois se pensarmos em termos de hospitalidade, conforme 
proposto pelo filósofo, o estrangeiro é questionado pelo hospedeiro porque este quer saber seu nome, de onde vem, i.e., quer se precaver para ter certeza que não dará abrigo a alguém que poderá destruir o seu lar e a si próprio. Se o hospedeiro sentir receio, é possível que não abra as portas da sua casa, não enfrentando assim uma relação de hospitalidade. Caso o hospedeiro se contente com as repostas do estrangeiro, abrirá as portas de sua casa para recebê-lo. No convívio com o hóspede, será questionado por ele, visto que esse estrangeiro, ao tentar se adaptar às regras do lugar, acabará muitas vezes por questionar certos valores pertencentes ao espaço no qual está inserido. Esses valores já estão, muitas vezes, internalizados, e, por conta deste contato, ficam novamente expostos e suscetíveis às novas condições. E, também, por desconhecer as regras do lugar, o estrangeiro, talvez sem intenção, corra o risco de romper com essas regras, poderá transgredi-las, poderá deslocar a verdade posta no local que lhe deu abrigo.

Nesse sentido, ao permitir a hospitalidade, i.e., ao permitir que a relação aconteça, sempre haverá em paralelo algum grau de hostilidade, um conflito, pois o filósofo francês entende que o ato de "inquérito", que o hospedeiro realiza com a intenção de dar ou não abrigo ao que vem de fora, é tão violento, ou apropriador, quanto o fato de o hóspede, voluntária ou involuntariamente, colocar em xeque as regras, ou a verdade do lugar (Derrida, 2003: 21-27).

Em se tratando da hospitalidade incondicional proposta por Derrida, supõe-se que para receber o outro incondicionalmente, enquanto outro absoluto, ou seja, recebêlo sem lhe perguntar o nome, sem lhe exigir reciprocidade, é preciso romper com as leis da hospitalidade corrente, ou, da hospitalidade de direito. É preciso, segundo Derrida, transgredir essas leis, porque elas não permitem que se hospede o outro sem que se conheça a sua origem e o seu nome de família. As leis condicionam a hospitalidade a um pacto entre o hospedeiro e o hóspede. Esse pacto, por sua vez, impede a hospitalidade num sentido incondicional do termo. Seria necessário, portanto, para instaurar uma hospitalidade fundada na incondicionalidade, um rompimento com o pacto imposto pela hospitalidade de direito (p. 23).

Ao mesmo tempo, Derrida, a despeito das aparentes contradições, reconhece que um pacto é necessário e, até mesmo, é indispensável para que seja possível o início de uma relação de hospitalidade. Além disso, indica esse pacto como o primeiro impulso para que o hospedeiro exercite a possibilidade de uma hospitalidade incondicional, i.e., a possibilidade do impossível. É justamente a impossibilidade de uma hospitalidade incondicional que coloca em progressão, em crescimento e aprimoramento constante, 
um ato de hospitalidade. Desse modo, por meio de um processo progressivo abre-se no por vir a possibilidade de um ato de hospitalidade incondicional: “[...] Mas, se a hospitalidade não pode ser incondicional, é preciso dizer, ao mesmo tempo, que uma hospitalidade incondicional é impossível, é o próprio impossível” (Perrone-Moisés, 2007: 45).

Com essa breve exposição do tema, podemos considerar que nossa ideia inicial, de uma dimensão filosófica e uma dimensão política no discurso bermaniano, instaurase quando o teórico, segundo nossa leitura, determina uma relação incondicional com o outro como horizonte para uma ética do traduzir, mas impõe condições para que essa relação seja determinada como tal. Porém, há uma possibilidade de que esse horizonte incondicional e impossível seja justamente a abertura, e não o fim, e, por isso, o que possibilita que a relação, mesmo que condicionada, aconteça - porque ela vai acontecer, essa é a condição de ipseidade. E, desse modo, o que pode parecer uma contradição no discurso de Berman é, no limite, o desdobramento de uma reflexão em diversos níveis, porém inseridos em uma dimensão do pensamento do teórico. Dessa forma, se a norma, se a lei de um determinado espaço pede o fechamento da entrada do outro, em um nível poético Berman impõe o contrário, impõe a abertura, que deve ser projetada na sua totalidade, pois, num primeiro momento, se faz necessário enfrentar a lei com toda a força. Por outro lado, a existência dessa lei é, também, condição necessária para que se apresente no âmbito da impossibilidade uma chance para a possibilidade; para que o contrário daquilo que a lei rege tenha a chance de se fazer valer, o teórico francês se expõe ao perigo de sucumbir a essa mesma lei. E, mais além, ${ }^{2}$ pensando em transformar essa lei, ou essa condição, e não destruí-la, ele busca elaborar uma ética de convivência, mantenedora de um novo espaço para o fazer tradutório.

Poderíamos dizer, seguindo esse raciocínio, que Berman seria um crítico da sua própria crítica, nos moldes como Hillis Miller elabora no seu artigo "O critico como hospedeiro" (1995). Berman seria um desconstrutor do seu discurso, ao invés de estar se contradizendo. Ele seria, ao mesmo tempo, o parasita e o hospedeiro das suas ideias. Aquilo que acontece, então, com o leitor do texto de Berman, é possível supor, é antes

\footnotetext{
${ }^{2}$ A reflexão nessa passagem se dá a partir da leitura de textos de Berman publicados posteriormente àqueles descritos nas referências deste trabalho, porém, não pretendemos desenvolver tal reflexão nesse momento da nossa pesquisa. Deixaremos uma elaboração desta reflexão para a continuidade da nossa pesquisa, em um próximo trabalho.
} 
uma oscilação entre os níveis do discurso do autor do que a percepção de contradições. E para dar continuidade a essa reflexão:

Se a palavra "desconstrução" designa o processo de crítica e a palavra "oscilação" designa o impasse alcançado através desse procedimento a "indeterminabilidade" designa a experiência de um movimento incessante na relação do crítico com o texto. (Miller, 1995 [1990]: 48)

Contudo, mesmo que se deixe de lado a ideia de contradição, substituindo-a pela ideia de oscilação, ainda assim há a necessidade de se estudar quais as implicações que essa questão traz para o pensamento bermaniano, visando, com isso, uma continuidade desse suposto "movimento incessante" através da pesquisa iniciada neste artigo.

Outra questão fundamental para nossa problematização, que desponta da reflexão derridiana, é o não reconhecimento, por parte do filósofo, de uma relação que não tenha qualquer grau de apropriação, visto que violentar, ou se apropriar do outro, é fator inerente ao processo de construção da relação. Desse modo, podemos concluir que, tendo a hospitalidade incondicional como horizonte, a relação, em alguma medida, acontecerá: uma relação que se constrói a partir das diferenças e, portanto, disposta ao enfrentamento dos perigos e chances que se fizerem presentes em cada ponto desse movimento. E ainda, à diferença de Berman, Derrida não acredita na possibilidade de se mensurar o grau de apropriação em uma relação, pois sua reflexão tem como pressuposto que não se pode prever o por vir desse processo. Derrida também reconhece que a apropriação acontece tanto por parte do hospedeiro quanto por parte do estrangeiro, assim, ambos se modificarão durante a relação, pois terão seus valores simultaneamente questionados e misturados. Berman, além de pressupor a possibilidade de se mensurar o grau da apropriação, quando estabelece um conceito de apropriação não cogita que o outro, de algum modo, também se apropria do próprio e também pode ser fecundado por ele.

O próprio, nesse caso, também é o estrangeiro, pois a condição de estrangeiro, sobre a qual fala Derrida, é reconhecida dependendo da perspectiva que se toma, porque, para aquele que chega de fora, aquele que lhe hospeda nada mais é do que um estrangeiro pelo seu ponto de vista. 


\section{"Um ato de tradução só pode ser poi(é)tico"}

Uma vez que nosso objeto de estudo se define a partir de uma concepção de tradução como relação, concluímos que a violência, sendo inerente à relação, também o é ao fazer tradutório, portanto, no ato de tradução o enfrentamento também se faz necessário. Como analisa Cristina Carneiro Rodrigues (2006), ressaltando a relação entre o outro e o próprio da tradução, por um viés derridiano:

Derrida sustenta que "a escritura não se pensa fora do horizonte da violência intersubjetiva" e nada escapa radicalmente a ela: nem conhecimento, nem linguagem são estranhos à escritura e à violência. A partir dessas afirmações entende-se a impossibilidade de haver tradução que não envolva algum tipo de violência, completamente alheia a alguma relação de dominação. (2006: 201, grifo nosso)

Rajagopalan (2000) conclui de forma bastante objetiva a discussão sobre a questão da violência na tradução ao afirmar:

Segundo a ótica dessas teorias [da tradução, inspiradas em reflexões pós-modernas], toda tradução, [...] passa por um ato de violência. Em outras palavras, a violência não é um mal que (infelizmente) atinge a tradução em muitos casos, que, portanto, pode e deve ter sido evitada a qualquer custo. Traduzir seria apropriar-se do texto dito "original". E toda apropriação, por sua vez, se processaria mediante exercício de violência. Longe de tentar eliminar a violência do ato tradutório, ao teórico de tradução caberia perguntar quais as condições que propiciam a violência e quais as formas de resistência que as vítimas oferecem com ou sem êxito. Ou seja, a violência da tradução, [...], passa a ser questão a ser investigada e compreendida, e não vista como fonte de embaraço. (2000: 124-5)

Dando movimento a nossa discussão é possível, agora, promover um deslocamento da noção de tradução até aqui debatida. Passaremos, então, de uma noção de tradução como relação para uma noção de tradução como construção da relação, nos termos da reflexão de Cardozo no ensaio "Tradução e o trabalho de relação: notas para uma poiética da tradução" (2009). Nesse ensaio o autor flagra nos discursos sobre a tradução - tanto nos que se fundam no pressuposto da identidade quanto nos que defendem a condição da diferença - variações de um discurso da relação e propõe, a partir disso, um (re)equacionamento da concepção de tradução com base na noção de relação, para, por fim, discutir a tradução como trabalho. Assim, Cardozo articula sua noção de tradução "como um trabalho por fazer. [...] Um trabalho de relação, no sentido de um trabalho que tem lugar no fazer, na construção da relação (das relações)" (2009: 186, grifo do autor). 
Nesse sentido, Cardozo percebe o fazer tradutório tal qual Derrida percebe um ato de hospitalidade, um ato que só pode se dar na passagem, como um trabalho por fazer, como um trabalho em construção. Cardozo entende a tradução como "poiesis":

[...] como um trabalho, como um fazer que se vale de possibilidades diante das impossibilidades impostas pela condição da relação [...] Um ato de tradução só pode ser poiético. [...] Enfrentá-la [a reflexão sobre a condição da relação], com suas chances e perigos, é o mínimo que se pode fazer diante do fato de que, a despeito de nossas compreensões por vezes tão divergentes, em alguma medida, a relação acontece. (Cardozo, 2009: 187-8, grifos do autor)

Promovemos, com isso, uma desconstrução da reflexão bermaniana, em especial quando percebemos que a tradução é uma relação que não está dada e, portanto, é uma relação que não pode ser condicionada a apenas um tipo de relação. Concluímos das reflexões de Derrida (sobre a relação de hospitalidade) e de Cardozo (sobre a tradução como relação) que a tradução pode ser anunciada como uma relação, mas que comporta uma multiplicidade de modos de relação: relações de diversos tipos e em diferentes níveis, relações imprevisíveis, que só podem ser enfrentadas com suas chances $e$ perigos. E essas relações só irão se apresentar no decorrer da "[...] construção e do equacionamento [ou, no trabalho] de uma relação no ato de tradução [...]" (Cardozo, 2009: 185). É desse modo que a tradução, neste artigo, se afirma como construção da relação.

E, ao promovemos essa desconstrução, promovemos, em alguma medida, aquilo que o próprio Berman nos faz intuir no final do seu ensaio "A tradução em manifesto": a extensão da sua reflexão, a suplementação da sua reflexão, partindo de dentro do espaço da tradução para dialogar com outros textos, de outras áreas, no nosso caso, a filosofia de Derrida, e, assim, procuramos dar à discussão interna da área novos ares.

Cabe, portanto, enfatizar que a problematização da noção de relação realizada neste ensaio, ao provocar uma reelaboração da noção bermaniana de relação a partir do diálogo com a noção de hospitalidade derridiana, não descarta a discussão sobre a tradução como relação proposta por Berman. Ao contrário, enxerga-a como mola propulsora, como uma abertura, um impulso progressivo visando dar mais complexidade e um maior aprofundamento às reflexões já instauradas no âmbito da pesquisa contemporânea sobre tradução. 


\section{Referências bibliográficas}

BERMAN, Antoine (2002 [1984]) A prova do estrangeiro: cultura e tradução na Alemanha romântica: Herder, Goethe, Schlegel, Novalis, Humboldt, Schleiermacher, Holderlin. Trad. de Maria Emília Pereira Chanut. São Paulo: EDUSC.

(2007 [1985]) A Tradução e a letra, ou, o albergue do longínquo. Trad. de Marie-Hélène Catherine Torres, Mauri Furlan e Andréia Guerini. Rio de Janeiro: 7 letras.

CARDOZO, Mauricio M. (2009) "Tradução e o trabalho de relação: notas para uma poiética da tradução". Márcia Pietrolongo (org.) O trabalho da tradução. Rio de Janeiro: Contra Capa.

DERRIDA, Jacques \& DUFOURMANTELLE, Anne (2003) Anne Dufourmantelle convida Jacques Derrida a falar Da Hospitalidade. Trad. de Antonio Romane. Rev. Técnica de Paulo Ottoni. São Paulo: Escuta.

MILLER, J. Hillis (1995/1990) "O crítico como hospedeiro". A ética da leitura. Trad. de Eliane Fittipaldi e Kátia Orberg. Rio de Janeiro: Imago.

PERRONE-MOISÉS, Leyla (2007) "Entre o perigo e a chance - Propostas de Derrida são convite a atravessar o abismo na corda bamba". Dossiê: Jacques Derrida. Cult - Revista Brasileira de Cultura 117, p. 44-64.

RAJAGOPALAN, Kanavillil (2000) "Traição versus transgressão: reflexões acerca da tradução e pós-modernidade". ALFA - Revista de Linguística 44, p. 123-130.

RODRIGUES, Cristina C. (2006) "A lógica da suplementaridade". Élida Ferreira \& Paulo Ottoni (orgs.) Traduzir Derrida: políticas e desconstruções. Campinas: Mercado de Letras.

SCHLEIERMACHER, Friedrich (2001) "Sobre os diferentes métodos de tradução". Werner Heidermann (org.) Antologia bilíngue - Clássicos da teoria da tradução. Volume 1 - Alemão/Português. Trad. de Margarete von Mühlen Poll. Florianópolis: UFSC/NUT. 